Article

\title{
Migrating (Grand)Parents, Intergenerational Relationships and Neo-Familism in China
}

by

Dr. Yan Zhao (Corresponding author)

Faculty of Social Sciences, Nord University

Postboks 1490

8049 Bodø

Norway

yan.zhao@nord.no

+4775517438

Yu Huang

Vanke Meisha Academy

33 Huanmei Road, Yantian District

518000, Shenzhen

China

yvonne201588888@yahoo.com; huangyu@vma.edu.cn

+8618028722828

Keywords:

domestic migration, elder migrants, descendent/neo-familism, intergenerational relationship, grandparenting

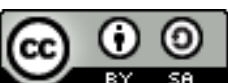

This work is licensed under a Creative Commons Attribution-ShareAlike 4.0 International License. 


\section{Abstract}

Based on a case study in one residential community in Shenzhen, China, this article explores the relationship between the migration of elder (grand)parents and the intergenerational relationship between the elders and their adult children. Specifically, we analyse how the intergenerational relationship influences and is influenced by the migration of the elders. The empirical data consists of eight qualitative in-depth interviews with elder migrants, who primarily migrated for helping with childcare. The analysis is embedded in theoretical discussions around Chinese descending/neo-familism (Yan, 2011, 2016), which depicts the significant changes that have taken place in Chinese family life, and new perceptions on the traditional ideals and norms regarding family relations in China (e.g. the notion of filial piety). Based on the analysis, this article argues that the migration of the elder (grand)parents is one specific form of descending/neo-familism, which entails an intergenerational solidarity that builds upon intimacy, with the focus and meaning of life flow downward to the third generation, as well as entailing aspects of selfsalvation (Yan, 2017). However, it also identifies tensions between the generations that are further intensified by the migration, most notably the elder generation's loss of autonomy and authority within the joint family structure. Furthermore, this article also raises some suggestions for social work intervention for this group.

Keywords: domestic migration, elder migrants, descendent/neo-familism, intergenerational relationship, grandparenting

\section{Acknowledgements}

We thank the anonymous referees for their valuable comments, which has helped us to improve the article. We are also grateful for the comments that we received from the participants of The $6^{\text {th }}$ Sino-Nordic Gender and Women's Studies Conference, 'Age, Agency, Ambiguity - Gender and Genderation in Times of Change' in Oslo in August 2017. 


\section{Introduction}

This article explores the experience of Chinese elder parents ${ }^{1}$ who migrate domestically (or 'migrating grandparents') to help their adult children with childcare. Specifically, we examine the relationship between the migration of elders and their intergenerational relationship with their adult children, or the second generation.

The migration of elder (grand)parents we study is one part of the large-scale domestic migration in contemporary China that has taken place since the economic reform in the 1980s. A recent report on China's migrant population development demonstrates that the total migrant population had reached 247 million, accounting for $18 \%$ of the total population, while the elder migrants accounted for $7.2 \%$ of the migrant population (National Population and Family Planning Commission, 2017). Nevertheless, this population has not yet received much attention in current research, in either migration studies or on studies of families and intergenerational relationships. The explanation can be that the proportion of this group is relatively small. However, the numbers in this group have increased dramatically in recent years with the acceleration of the aging process, and the fact that the first generation of 'one-child policy' parents has gradually reached their late 60s (Meng et al., 2004).

Existing research shows that the majority of elder migrants migrate for the purpose of helping the second generation, particularly with childcare (Li \& Gan, 2017; Meng et al., 2004). An important context is a lack of sufficient institutional support around childcare in contemporary China. For example, maternity leave in China is by law 98 days, up to a maximum of four months (Special Rules on the Labour Protection of Female Employees, 2012). Nevertheless, the average age for enrolling a child in kindergarten is approximately three. Grandparents often fill this gap regarding childcare. Childcare in China therefore relies heavily on grandparents (Chen, Liu, \& Mair, 2011; Goh, 2009; Zhong \& Li, 2017).

Hence, the migration of elder (grand)parents touches upon the question of intergenerational relationships, which are not only decisive in decision-making, but also shape the parents' expectations and after-migration experiences, thereby influencing their life quality and well-being. Thus far, the inter-generational relationship is an ignored aspect in the existing research on migration, often 
mentioned as the cause of the migration. It needs to be further scrutinized to fully understand the rise of migrating grandparents, and how it is related to other processes in Chinese families. Consequently, this article aims to explore this understudied aspect with the following research question: How does the intergenerational relationship between the elder (grand)parents and their adult children influence and become influenced by the migration of elders?

With a focus on the needs of migrant grandparents, this article seeks to contribute to the development of social services not only to this specific group, but also to the elder population in general, as the study provides insight on changes in family patterns and relations in China. Though the case may seem country-specific, we argue that the knowledge and perspectives generated in this article are also relevant to an international audience, not only because other non-Western and/or more collectivist countries have witnessed similar changes in families as to processes of modernization and individualization (Ko \& Hank, 2014; Mehta \& Thang, 2012), but also because different ideals and cultural practices of families travel as part of a broader global migration and transnational processes (Xie \& Xia, 2011; Nedelcu, 2017).

\section{Understanding family relations in China - theoretical perspectives}

The Chinese social anthropologist Fei Xiaotong (Fei, 2008) writes that in comparison to Western families, in which the core relationship is the horizontal one between husband and wife, the core relationship in China is the vertical one between parents and children. The intergenerational relationship is therefore the key to understanding family life and relations in China. Another clue to understanding family relations is to look at the relationship between the individuals and the family. In this respect, Chinese families are often categorized as collectivist (Hofstede \& Bond, 1988; Hofstede, 1993). Although individualism and collectivism should be understood as ideal types that help to grasp the key features of the different types of families (Skytte, 2001), this categorization fails to grasp recent changes that have taken places in families. Several empirical studies on contemporary Chinese society identify individualization as an important clue to understanding ongoing social processes (e.g. Hansen \& Svarverud, 2010; Hoffman, 2010). The individualization 
process in China, which is characterized as 'state-managed' and not relying on the ideology of Western individualism (Beck \& Beck-Gernsheim, 2010; Yan, 2011), depicts the rise of individuals and new ideas that oppose the collective-oriented, Confucianism-based traditional culture, and thus not only changes people's relationship with their families, but also their perception of traditional ideals and norms regarding family life, e.g., on the notion of filial piety, the core and basic norm in guiding family relations in China (Ikels, 2004; Whyte, 1997).

One who has studied these changes is the American-Chinese anthropologist Yan Yunxiang, in his theorization on descending/neo-familism (Yan, 2011, 2016). Yan's theories attempt to capture the bottom-up daily changes in Chinese families, which are different from both traditional familism, which centres on the notion of filial piety and unconditional obedience and submission from the junior to the senior generations (Cohen, 1976; Fei, 2008), and the decline of familism brought by a topdown family revolution in Mao's era (Yan, 2003). With the concept of descending familism, Yan describes a different model of intergenerational solidarity that builds upon intimacy between the elder and younger generations, and a new and flexible form of family structure, in which the focus and meaning of life flow downward to the third generation of grandchildren (Yan, 2016). In particular, Yan considers the emergence of intergenerational intimacy, in the form of increased communication, the sharing of emotions and a better understanding between the generations, as a breakthrough from the traditional Chinese family culture, in which intimacy was suppressed in order to maintain hierarchy and parental authority. As a result, there is a new understanding of filial piety that no longer requires the submission and obedience of the younger generation (Yan, 2016; Chen, Liu, \& Mair, 2011; Zhong \& $\mathrm{Li}, 2017$ ). Neo-familism is a further theorization of descending familism, which also entails a notion of 'sacrificing the small self for the realization of the greater self, with a concrete, affective and materialistic goal' (Yan, 2017).

We consider Yan's theories of descending/neo-familism to be relevant and helpful to our analysis of the intergenerational relationship in migrating families. It not only provides us with a broader context to understand the phenomenon of elder parents migrating to reunify with their children's families, but also offers us theoretical tools to help analyse the intergenerational relationship before and after the migration. On the 
one hand, our empirical finding mirrors the key elements of Yan's descending/neo familism; on the other hand, we also identify the tensions between the generations in the new model of a joint household after migration, which we argue to be a specific form of descending familism. Yet, the question remains: Whether and to what extent are these tensions a result of the migration? This is something we aim to contribute with in the discussion of Chinese descending/neo-familism.

We have also referred to the literature on grandparenting to better understand the inter-generational relationship in China. Though common in many societies, grandparenting is different in its extent and forms. At the micro level, it is driven by the needs of the parents, whereas at the macro level it is greatly influenced by social norms and cultural contexts (Chen, 2014). In the Chinese (and East Asian) contexts, grandparenting often centres around the Confucian notion of filial piety (Ko \& Hank, 2014; Silverstein, Cong, \& Li, 2006). Furthermore, traditional grandparental roles in East Asia tend to be related to fostering intergenerational bonds and extending family heritage (Cong \& Silverstein, 2012), which indicates that grandparenting in a traditional sense contains not only basic daily caregiving, but also educating and mentoring. Grandparenting has also been studied in relation to social changes and structural processes (Mehta \& Thang, 2012). Two structural changes are specifically identified, and considered to challenge the traditional grandparental roles in China: The one-child policy and the mass internal labour migration, both of which started to take place in the early 1980s (Ko \& Hank, 2014). A significant consequences of the one-child policy is that raising the 'precious single child' has become an 'intergenerational joint mission' between parents and grandparents (Goh, 2006). As to internal migration, the studies have mostly focused on the grandparenting of a large number of 'left-behind' children in rural areas (Cong \& Silverstein, 2012). Little attention is paid to the cases in which grandparents migrate for caregiving. Hence, this article also intends to make a contribution to further understanding the question of grandparenting and the internal migration.

\section{Methodology}

The analysis in this article builds upon a qualitative study on accompanying migrating parents in a residential community in Shenzhen. There are several reasons for 
choosing Shenzhen and this community as our research site. Firstly, Shenzhen has one of the largest migrant populations in China, and its population also reflects the pattern of China's internal migration over the last 30 years (Ye, 2013). The community we chose has a high proportion of residents with migration backgrounds, with the floating population over 60 years old reaching $10 \%,{ }^{2}$ which is close to the national level of $10.41 \%$ (National Population and Family Planning Commission, 2017). Secondly, the researcher who conducted the interviews had an affiliation with this community through her previous internship as a social work student at the community social work station. This affiliation allowed her to receive the support from the street-level cadres and the social work station necessary to conduct data collection in China. This affiliation has also provided the researcher with the necessary knowledge about this community and its residents.

The empirical data consists of in-depth interviews with eight migrant elder (grand)parents. All of them moved to Shenzhen from other provinces with the primary purpose of taking care of their grandchildren. Another thing these informants shared is that they do not have their household registration (Hukou) in Shenzhen (floating population). In China, there are strict requirements for moving Hukou, which is not only a system for documenting population information, but also one for distributing public resources, and thus controlling the internal migration ( $\mathrm{Wu}, 2013)$. Not having a Hukou in Shenzhen means limited or no access to local welfare benefits and public services. One of the authors conducted the interviews during her two stays in this community, one week in August 2016 and one week in January 2017.

The first informant was recruited with the help of the social work station. Thereafter, we recruited other informants through the snowball technique. We were quite open when recruiting the informants, with the following standards: 1) The informants were in their 60 s or thereabouts, and they mainly migrated to help with childcare. We therefore focused on those who were relatively healthy and not heavily in need of care themselves; 2) They had lived continuously in Shenzhen for more than six months. The informants were between the ages of 58-69, with five females and three males. The length of time they had lived in Shenzhen varied from three to 10 years. The informants were of different educational and economic backgrounds. Three of them hold a rural Hukou, which means that they had even more limited access to the 
public benefits and services compared to those with an urban Hukou. Four informants moved to Shenzhen together with their spouses, one was a widow and the rest chose to move alone, leaving their spouses at home. An overview of the informants' background can be found in Table 1:

Table 1: Background of the informants

\begin{tabular}{|c|c|c|c|c|}
\hline No. & 1 & 2 & 3 & 4 \\
\hline Age & 65 & 69 & 67 & 58 \\
\hline Gender & Female & Female & Male & Female \\
\hline $\begin{array}{l}\text { Household } \\
\text { type }\end{array}$ & Urban & Urban & Urban & Rural \\
\hline $\begin{array}{c}\text { Home } \\
\text { province }\end{array}$ & He Nan & Shan Dong & Zhe Jiang & Hei Long Jiang \\
\hline $\begin{array}{c}\text { Educational } \\
\text { level }\end{array}$ & High School & Primary School & University & Primary School \\
\hline $\begin{array}{c}\text { Residency of } \\
\text { spouse }\end{array}$ & Shenzhen & Widowed & Shenzhen & Hometown \\
\hline $\begin{array}{l}\text { Length of } \\
\text { staying in } \\
\text { Shenzhen } \\
\text { (Year) }\end{array}$ & 10 & 10 & 5 & 3 \\
\hline No. & 5 & 6 & 7 & 8 \\
\hline Age & 61 & 63 & 68 & 64 \\
\hline Gender & Male & Female & Female & Male \\
\hline $\begin{array}{c}\text { Household } \\
\text { type }\end{array}$ & Urban & Urban & Rural & Rural \\
\hline $\begin{array}{c}\text { Home } \\
\text { province }\end{array}$ & Jiang Xi & Shan Dong & Hu Nan & $\mathrm{He} \mathrm{Bei}$ \\
\hline $\begin{array}{c}\text { Educational } \\
\text { level }\end{array}$ & High School & Middle School & Illiteracy & Middle School \\
\hline $\begin{array}{c}\text { Residency of } \\
\text { spouse }\end{array}$ & Shenzhen & Hometown & Hometown & Shenzhen \\
\hline $\begin{array}{l}\text { Length of } \\
\text { staying in } \\
\text { Shenzhen } \\
\text { (Year) }\end{array}$ & 7 & 9 & 6 & 4 \\
\hline
\end{tabular}


We have chosen to conduct a narrative analysis before a more focused thematic analysis. When doing analysis, we focus on both the 'told' and the 'telling', which not only allowed us to look at the sequential and structural order of how interviews as narrative events unfolded (Mishler, 1986; Riessman, 2008), but also enabled us to examine the interactions during the 'telling' as a situational context for the 'told'. Consequently, we did not interpret the interview data as facts or 'true' stories; instead, one version of the storytelling developed in a specific context. We consider this stage of analysis important, especially given that the number of interviews was relatively small, as it enabled us to go in depth into the interview data, with a special attention to what the interviews highlighted and what might have been downplayed. Based on the narrative analysis, we then conducted a thematic analysis, specifically focusing on intergenerational relations, decision-making and life changes after the migration. The analysis is divided into two parts. First, we analyse how intergenerational relations have influenced the informants' decision-making on migration; second, we analyse how migration and joint-living have influenced intergenerational relations.

\section{Inter-generational relationships and decision-making}

As previously mentioned, we chose to focus on the elder parents who migrated to Shenzhen to help with childcare. It is therefore not surprising that all informants referred to this reason when talking about their decision-making. All said that the migration was initiated by the second generation, mostly upon the birth of a grandchild. In addition, they mentioned other push-and-pull factors: pull factors such as better medical facilities in Shenzhen, the happiness of living with children and grandchildren, and the opportunities of experiencing a metropolitan city like Shenzhen, and push factors like fear of being 'empty-net elders', an expression of a tragic, miserable and lonely elder life without offspring. In our analysis, we focus on how the informants talked about and perceived their role in childcare, and how to understand the intergenerational relationship from these narratives and perceptions. 


\section{Grandparent caregiving - a reliable duty}

One common, dominant narrative we identified concerning the informants' perception of childcare was 'grandparents on duty':

I only have one son, so I do not have a choice. My daughter-in-law was pregnant shortly after they got married. My son wanted us to come and take care of her and later the baby. The parents of my daughter-in-law could not come because they were taking care of their son's baby. We also discussed hiring a nanny, at our expense, but my son worried about the safety issues. After all, you do not feel totally assured letting a stranger take care of your baby. Finally, we decided to come. Already around that time, we had decided that we would leave when the baby got older. Otherwise, I have nothing to do here. I had no other expectations. I came to finish my mission. It was like switching duties, off-duty [retirement] in my hometown, and then on-duty in Shenzhen. (Informant 5)

To help with baby care is therefore a choice of 'no choice', which reflects the norm of grandparent caregiving in China (Goh, 2006; Ko \& Hank, 2014). Childcare becomes an inevitable part of becoming a grandparent, or what the informant described as a 'duty'. He also compared childcare to his full-time work before retirement, indicating that childcare is an obligation you have to fulfill. Informant 6 also described herself as a 'grandma on duty'. She even added, '24 hours a day, and all services'. In other words, the duty of childcare is even more demanding than full-time paid work. Similarly, Informant 7 called childcare 'obligatory work', or yiwu laodong in Chinese, which can also mean 'unpaid work'. These expressions indicate that childcare is not something the elder parents like doing; instead, it can even be said to be a sacrifice. Another aspect in the above narrative that is rather representative is that most informants considered the migration as a temporary solution in the decision-making. Yet, we have one exception.

Informant 2 is a widow, whose only son works in Shenzhen. Unlike the other informants, when deciding to migrate, she intended to migrate and live permanently with her son. She explicitly talked about her future needs for elder care in the decisionmaking. She referred to the old Chinese saying, 'bearing and rearing a son for one's old age'3 to justify her expectation for filial piety and care. Fear of being an 'emptynest elder' was also mentioned several times. Still, upon the question of whether her migration was on her own initiative, she answered: 
Not really. When my grandson was born, my daughter-in-law wanted to hire a nanny because she wanted to keep working. I thought, why spend this money? Nannies are not family, and they are often not willing to bear the responsibility for their actions. I am different. I am the grandma. If something happened, I would solve it myself and then tell them [the parents] later. A nanny would probably call and ask what to do, right? Then how can they concentrate on their work? So if I came to help, they would feel much more secured and relaxed. (Informant 2)

Even though the expectation behind her migration was directed towards her own need for filial care, the decision-making was based upon the needs of the second generation for childcare. Similar to Informant 5, she also considers herself a better alternative than a nanny. First, to save money. For whom? The second generation. It is worth noting that when Informant 5 was considering a nanny, he emphasized this would be at their expense. Second, more responsible and dedicated - so that the second generation can concentrate on their careers. 'Grandparents on duty' as a better alternative to a nanny is hence another common narrative. Both quotes further illustrate that the elder parents perceive the interests of the two generations to be closely bounded, which are considered as a whole in the informants' decision-making on migration. Yet, for Informant 2, it can also be said that 'parents-on-duty' becomes a good and natural timing for her to migrate permanently to reunify with her son.

\section{Pride and understanding - the elder parents' perception of their children's migration}

Even though 'parents-on-duty' is a dominant narrative, we cannot simply reduce informants' decision-making to a question of duty. There is also an emotional dimension. In the interviews, all informants complained about the busy second generation: They are so occupied with their work that they barely have time to be with their elder parents. On the surface, this narrative concerns the intergenerational relationship after the migration. Nonetheless, aside from these complaints, we can also read pride and great understanding that these parents showed to their children, which had influenced their decision-making to migrate. To illustrate this, we cite two of our informants:

My son works in a big company. He has worked in Shenzhen for many years now. He keeps working all the time and seldom rests. He does not even have time to eat a proper meal. My daughter-in-law is busy too. That's the reason why we are here, to make food and help them with housework. (Informant 1) 
I lived in the countryside all my life. I had little schooling, and don't know so much, but my son is very capable. He is educated, and now he has managed to settle down in Shenzhen. The relatives and friends in our village admire us. But I know it is not easy to live in a big city. My son is very busy all the time. Mortgage, car loan, he has a lot of pressure. So I do not expect much. The only thing I expect is to help him, and to make his life easier. (Informant 7)

Even though both informants belong to the category of 'grandparents-on-duty' addressed earlier, their narratives here reveal that duty is only one aspect of the decision on migration. To migrate, including the decision to take care of grandchildren, is also their own choice based on an understanding towards the second generation regarding their economic and career situation in Shenzhen. As new first-generation migrants, ${ }^{4}$ they probably have more challenges to survive in the city than others. This understanding clearly contains strong familial affections, in particular parental love, as well as emotional support for the children's decision to stay in Shenzhen. This finding complies with Yan's argument on a change of present intergenerational relations, which has transformed from parental authority to an intergenerational solidarity based on emotional intimacy (Yan, 2016).

The informants' emphasis on their children's busy work is also an implicit way to talk about their children's success of having managed to achieve a career and find their own space in metropolitan Shenzhen. This is not only considered as a personal achievement but also an achievement of the family, which is somehow obvious in the second excerpt when the informant told that it is the whole family ('us') whom the other villagers admire. Pride is therefore another important element in the informants' decision-making.

In the 'grandparents-on-duty' narrative, Informant 7 described childcare as unpaid work, implying her contribution was nearly 'self-sacrifice'. Put into the context of the parental pride, it can also be understood in relation to the central aspect of selfsalvation in Yan's conception of Neo-Familism (Yan, 2017): The elder grandparents sacrifice their small self for the realization of a concrete and materialistic goal, a better/easier life for the younger generation in Shenzhen. This pride also has to be understood in relation to Chinese utilitarianism, in which educational and career achievements are often considered the key to measuring personal success and 
happiness (Lu, 2001; Wang, 2006). It is in this context that we can identify the pride, which is otherwise quite implicit in these narratives.

\section{The inter-generational relationship after the migration}

Spatial proximity and emotional proximity

Even though decision-making on migration is overwhelmingly directed by the needs of the younger generation, the informants did expect some positive sides of migration, most important of all, proximity with the child and grandchild. The question then remains: How has migration possibly changed the elder parents' relationship with the younger generation? Has migration bought the generations closer to each other, and in what ways? A general narrative we can identify from our data is that migration has brought them into a much more proximate and intimate relationship with their grandchildren, but not necessarily with the second generation. To help illustrate this:

The young people are very occupied with their career [sigh]. I understand this. My son and daughter-in-law are very busy. Even though we live together, sometimes I only meet them once a week. This is then not much different from when I lived in my hometown. My main responsibility in this home is to take care of my grandson. They don't spend much time accompanying us. This made me sad, and I feel even lonelier than before. (Informant 2)

This excerpt illustrates well a paradox that several of our informants experienced after the migration, namely that physical closeness to their children does not lead to as close a relationship as they had expected. In this case, the informant felt that it was even more difficult to handle the loneliness while living under the same roof than with the physical distance before the migration. In this way, the proximity the informants expected is more of an emotional one, which the same informant emphasized when telling about her expectations about filial care from her son. She says:

When I get really old, I expect filial care from my son. Like now, I help him take care of his child, then later, he takes care of me. I am not only talking about economic support, but even more importantly, emotional support. I have medical insurance. So I can afford the medical treatment. But when you get ill, you still need someone to accompany you to the hospital. How can you go to hospital yourself when you are ill, right? (Informant 2)

This narrative complies with the findings of another study, which argues that the arrangement of childcare by the elder generation and their expectation of filial care 
can be understood as being part of a new intergenerational contract in a context, where the elder parents no longer take filial care from their children for granted (Zhong \& Li, 2017). Furthermore, as also shown in this quote, what the informant expects and values is the emotional side of care and support, such as being accompanied to health and medical services and spending time together. Several informants claimed that they had little communication with their children or childrenin-law. This was particularly hard for those who lacked a social network in Shenzhen, making them even more emotionally dependent on the children. Concerning proximity and communication, Informant 8 has an interesting narrative:

Right after my grandson was born, my daughter's mother-in-law came to take of care of her and the baby. They got along well with each other. My daughter was very grateful to her mother-in-law. They never quarreled or anything. After all, they do not have a blood relationship. One's own parents are somehow different. They can easily criticize you and you can easily get annoyed, because you know you can make it up with them later. So you see, our family is often noisy like we are quarreling and fighting with each other, hehe... [laughing]. (Informant 8)

On the surface, the informant seems to describe an intergenerational relationship full of small disagreements, or even small conflicts. Meanwhile, he seemed to enjoy this process of 'quarrelling', and then making up. He makes an interesting contrast between his daughter's relationship with them and with her parents-in-law. His daughter does not quarrel with her parents-in-laws, and they might be polite to each other, because there is a lack of intimacy and proximity. With this contrast, he is telling us that even though he and his wife 'quarrelled' a little bit with his daughter, the 'quarrelling' is itself a communication which indicates emotional proximity. This narrative complies with the narratives of other informants who complained that their children (-in-laws) seldom talked with them, and that they experienced the home in Shenzhen as desolate (quiet) and cheerless. This illustrates that the migrant parents long for a communication with the second generation, even though the communication can contain disagreements and 'quarrelling'. Again, emotional intimacy, which Yan (2016) identifies as the new element in understanding the intergenerational relationship in China, is visible here, perceived by the informants as an ideal for intergenerational relations. 
Conflicts around the grandchild and the power relations between the two generations As discussed, all informants migrated upon the second generation's need for childcare. It is the grandchild who brings the two generations together into a joint household. When two generations live together in one household, conflicts are nearly inevitable. When asking about the conflicts, all the informants talked about the conflicts arising in co-caring the grandchild. This is not surprising, as childcare is the main part of their daily life after migration. First and foremost, the conflict concerns a generational gap on how to bring up young children. For example, Informant 1, whose grandchild is school aged, answered our question on inter-generational conflicts as follows:

The biggest conflict is that we have very different views on our granddaughter's education. It started like one year ago when my son enrolled my granddaughter into different, additional tutoring classes. One is named Xue'ersi, very popular. They require the parents to participate in the class together with the child. In addition, you are expected to follow the class carefully and even make notes, so that you can help the child afterwards. My son and his wife are too busy, so I used to be there. But I am getting old and I often feel a lack of concentration and am sleepy in class. To be honest, this is too much for both Hanhan [granddaughter] and me. Poor Hanhan has too much homework from both the school and tutoring classes. ...... I think that parents should spend time with their child, instead of paying for these classes. This is waste of money and the child is made exhausted. But my son does not understand this. (Informant 1)

This quote reflects a general phenomenon in China that families invest heavily in children's education. Education turns to be one important part of the "intergenerational joint mission" (Goh, 2006) between parents and grandparents. To enroll the children into different tutoring classes outside normal school is very common. To disagree with this new mode of education and schooling is one source of intergenerational conflict. This excerpt also illuminates that the new mode of schooling requires not only economic resources, but also time and effort from both generations. When parents are busy, the requirements turn towards the grandparents. The informant expressed that some of the requirements are too high, and go beyond their abilities. However, not all informants are directly involved in their grandchildren's education. Being asked how the responsibilities and tasks regarding care and upbringing are divided, Informant 4 says:

The young people are in charge of our grandson's education, while I make food, feed him and accompany him to schools and other tutoring classes. 
(Interviewer: Has there been any conflicts?) Often! They don't know how to teach a small child. There is much yelling and crying. When I heard my grandson crying, I got uneasy and anxious, so I interfered in the situation. It often ended up with quarrelling between my daughter and me. My husband told me to not get involved in the education issues of our grandson, saying that, 'You have to accept that you are not in a position to decide over the upbringing.' Then I got angry and hurt. I am her mother! Why am I not in a position? (Informant 4)

While Informant 1 has a high school education, Informant 4 has only a primary school education, which may explain why Informant 4 was less involved in the third generation's education in comparison with Informant 1. However, both cases illustrate that the decision power on how to raise the third generation, in particular concerning educating, lies on the side of the second generation. Thus, we analyse the tensions described by both informants in relation to changes of power relations between the two generations, which concerns an understanding of filial piety and perception of knowledge.

Traditionally, filial piety entails an absolute obedience to the parents. The elders therefore have absolute authority in the family, holding the decision-making power in family affairs, including decisions on the education of the third generation. However, as several studies point out, the traditional notion of absolute obedience has been eroded as a result of several simultaneous social processes, including individualization and a series of institutional reforms in China (Yan, 2003; Lin \& Yi, 2011). When Informant 4 asked rhetorically, 'Why am I not in a position to decide,' it illustrates a tension between different understandings of filial piety and the loss of parental power, particularly intellectual power: Who is the knowledgeable one? In the traditional society, the elder's knowledge based on a long life experience was greatly valued. This is also why educating and mentoring have been part of the traditional role of grandparenting. Nevertheless, the idea of modernity and development relies heavily on science and technology. In general, the younger generation today is more highly educated than their parents, and they are more current regarding the new technologies. Hence, when the informant's husband told her that she is not in a position to decide, there is also a dimension of knowledge: The younger generation probably knows better what is the right thing to do. 
However, this aspect concerns not only migrant families, but also non-migrant ones. Based on our analysis, we argue that migration has further reduced the relevance of migrant grandparents' experiential knowledge, and thus their intellectual power and authority. For example, most of the informants describe feelings of alienation when living in a modern metropolitan city like Shenzhen. Several informants told that to take a bus alone in Shenzhen was challenging and scary, because the system is digitalized and too complicated. In this context, the younger generation has become knowledgeable, while the elder is ignorant. Informant 4 also says, 'When I am not strict with my grandson, they consider me spoiling the child; yet, when I scold him when he is naughty, they say I am not pedagogical.' This illustrates that the conflict is not necessarily about who is right or wrong. It concerns the switching of power between the two generations, not least the power of definition.

\section{Living under another's roof - belonging and the autonomy of the elder generation} We have already mentioned the feeling of alienation the informants had when living in Shenzhen. Yet, how do the informants experience their new home in Shenzhen? Do they feel at home? Except for Informant 1, whose wife and he live separately in their own apartment, other informants were very clear that the home in Shenzhen was owned by and belonged to the second generation, whereas the home in their hometown is their actual home. This is especially the case for the informants who lived in Shenzhen alone while their spouses remained in their hometown. One of them is Informant 4:

I am not familiar with Shenzhen. I do not have friends here, but I am not interested in getting to know new friends either, even the relatives of my sonin-law. They sometimes came to visit. When I was in my hometown, I used to invite my friends home. But here I feel I don't have a right to do so or decide anything. (Interviewer: Why?) When my daughter was small, she listened to me. But now, she is an adult and has her own family. I cannot take her home as my own. Not to mention, my son-in-law lives here too. (Informant 4)

This quote highlights that the informant does not have a sense of belonging, either to the city or the home which she considers as belonging solely to the second generation. ${ }^{5}$ Exactly because of this, she felt like she is not entitled to make any decisions. The feeling of not being at home is also related to living conditions in Shenzhen. Due to high housing prices, most of our informants live with their 
children's family in cramped small apartments, and had to share the bedroom with their grandchild:

We had to share the bedroom with Lili [granddaughter]. When she was small, it was ok. But it turned to be difficult after she started school. Lili has lots of homework, and used to do homework until $11 \mathrm{pm}$ every night. My wife usually goes to bed around 9pm, so she complains to me that she cannot sleep well. Once I woke up at midnight, and found my wife sleeping on the couch in the living room. Ai....[sigh] but the housing price is too high, we understand. [sigh] (Informant 8)

This excerpt illustrates well a tension in the joint household, which was caused by the different needs of the generations. In such cramped housing conditions, the elder migrant parents lack their own private space. Another informant also mentioned the challenges of a big family sharing the only toilet/bathroom. 'Each time I went to the toilet I felt uneasy and nervous because I always think someone may be waiting outside.' The lack of space, we argue, can strengthen the migrant parents' feeling of being a guest living under the roof of the host.

We also asked about the economic arrangements in the joint household. We find that when answering this question, the informants all emphasized that they were not economically dependent on their children. For example:

My son gives me some pocket money regularly. This is in addition to the money he gives me for the daily expenses of the whole family. This has to be clear, what is for what. Even though I don't need the [pocket] money, I still feel happy, because it shows his filial piety to me. (Informant 2)

We pointed out earlier that in the decision-making on migration, the elder generation perceived the interests of the two generations to be bounded together. Yet, when the informant said, 'This has to be clear, what is for what,' it demonstrates that the informant considers it important to have a separate economy after the migration. Like Informant 2, several other informants emphasized they do not rely on their children economically. Nonetheless, Informant 2 still feels happy, not for the money itself but for the gesture from her son, perceived as fulfilling filial piety. We interpret the informants' emphasis on economic independence as a stance to maintain their autonomy, which, we argue, was reduced by the migration. As we previously stated, they feel they are not entitled to make decisions since they do not own the house. 
We would also link the loss of autonomy to another aspect that we argued earlier, namely that migration makes the elder parents more dependent on the younger generation. In addition to the feeling of alienation and the loss of intellectual power that derive from this dependency, the Hukou system related to welfare distribution seems to contribute to these feelings. As mentioned, none of the informants changed their Hukou to Shenzhen, which limited their access to welfare benefits and public services:

Things are expensive here. I don't want to be a burden for them. Last time, I got ill and my daughter spent several thousand for the treatment and medicine because I do not have local medical insurance. I still feel guilty. I will move back to my husband when my granddaughter is a little bit older, and my daughter does not need my help anymore. Hey... [sigh], to come and to leave are all about the needs of children. We do not have a choice. (Informant 4)

This excerpt demonstrates how the rigid household registration system can lead to migrant parents' economic dependence on their children, and thus further weaken their autonomy. Access to public health services is a common concern among all the informants. Another representative aspect in this excerpt is the elder parents' fear of being a burden and their struggle between 'leave or stay'. Except for Informant 1, whose wife and he live in their own apartment, and Informant 2, the widow who had determined to live permanently with her son, all other informants said that they would leave after their children no longer needed them. Yet, nobody knew when. On the one hand, this highlights that the elder parents have prioritized the younger generation's needs over that of their own in the whole process of migration, not only in the decision to come, but also the decision to leave. On the other hand, we interpret the fear of being a burden in relation to the loss of autonomy. As shown, when the primary purpose of migration is to help with childcare, the elder parents often consider the migration a temporary one. Here, we argue that their experience of living jointly with the younger generations, in particular in a city like Shenzhen, with a high cost of living, can reinforce this perception, precisely because the migration has made the elder parents who do not want to lose their autonomy feel more dependent on the younger generation.

\section{Discussion and conclusion: Migration and Neo-Familism in China}

As addressed, the migration of the elder grandparents is a result of both 'fulfilling the duty' and an intention to support the second generation. Of particularly importance is 
the emotional side of the support, which is based on their understanding towards the situation of the children being migrants, intertwined with a parental pride as migration and settlement in a big city are perceived as an accomplishment for the entire family. Therefore, the migration of the younger generation strengthens the need for and practice of grandparents' caregiving, which adds an extra layer of meaning to migration as to the question of migration and grandparenting.

As to how migration has influenced the intergenerational relationship, our data indicates that physical proximity does not necessarily lead to an expected emotional proximity. Our analysis highlights that migration has made the elder parents more dependent on the second generation, thereby further reducing their authority (especially intellectual power) and autonomy as a result of an experience of alienation and a lack of belonging. Moreover, due to a lack of private space and loss of autonomy, they lack a feeling of being at home.

Based on the analysis, we argue that migration of the elder (grand)parents is one specific form of what Yan theorizes as descending or neo-familism (Yan, 2003, 2016). Firstly, the migration demonstrates an intergenerational solidarity centred on the needs of the younger generations - a descending focus from the elder generation which may entail self-sacrifice, e.g., a loss of private space and autonomy. Secondly, this solidarity displays an intergenerational intimacy as identified by Yan (2016). In particular, our data shows that the migrant parents value emotional intimacy. Their decision to migrate contains elements of such emotional intimacy, such as parental love, understanding and pride. Thirdly, the migration also illustrates a flexible family structure, as many migrant parents have maintained their own household in their hometown while living jointly with the younger generations, and some of them even live separately from their spouses.

Our finding also identifies tensions in this new form of descending/neo-familism. Most significant of all is how the migration has influenced the power relations between the elder parents and the second generation. The decision-making behind migration shows the younger generation's dependency on the help of the elder parents around childcare. This dependency is not only an economic one (e.g. childcare provided by grandparents as 'voluntary unpaid work'), but also an emotional one, particularly one 
of trust (e.g. childcare from grandparents is perceived as the most reliable). However, migration has switched this relationship and made the elder parents more dependent on the younger generation, most notably emotionally, yet also economically, hence leading to a loss of autonomy and decision-making power. Of course, this depends significantly on the economic background of the elder generation. As part of his theorization on Neo-Familism, Yan addresses the return of parental power based on his study of parental-driven divorce in a Chinese urban context (Yan, 2015). In contrast to Yan's case, in which the informants are mostly urban local residents, our finding indicates that migrant elder parents, especially those from a lower socioeconomic status or less developed regions, experience a loss of parental power and autonomy. Consequently, several informants consider the current migration and joint family structure as a temporary arrangement, which indicates a change in the elder parents' perception of family happiness. Moreover, this suggests that migration can potentially challenge the intergenerational exchange (of childcare and filial care) which the thesis of the neo-familism builds upon (Zhong \& Li, 2007; Yan, 2016).

As to the social work intervention, we call for special attention to this group of elders from the social work stations in residential areas, as their needs and situations are different from that of local elders. One approach would be to facilitate the establishment of a group for the elder migrant parents, with the purpose of developing activities and enhancing their social life. At the political and system level, we call for flexible welfare services for this group, as well as to recognize the need to develop a care system for the elder parents of the migrants based on their needs rather than on residency status, as our study indicates that most migrating elder parents tend to return. 


\section{End notes}

1. In Chinese, 随迁老人 (suiqian laoren).

2. The data is from the local social work station.

3. In Chinese, 养儿防老

4. Shenzhen was originally a small fishing village. It was developed into a big city after the economic reform, due to its geographical advantages of bordering Hong Kong. Therefore, a large majority of the city's population are migrants from other parts of the country. Yet, in this study, we focus on families that have relatively newly migrated to Shenzhen.

5. As well, the sense of belonging to the home in Shenzhen also concerns the migrant elders' status as 'in-laws', which is a complicated issue in studies on current family relations in China. As stated in the research question, we primarily focus on the old parents' relation with their adult children.

\section{References}

Beck, U., \& Beck-Gernsheim, E. (2010). Forward: Varieties of Individualization. In M. H. Hansen \& R. Svarverud, (Eds.), iChina, the Rise of the Individual in Modern Chinese Society. Copenhagen (pp. xiii-xx): NIAS Press.

Chen, F. (2014). Patterns of Grandparents Caring for Grandchildren in China. In D. L. Poston Jr., W. S. Yang, \& D. N. Farris, (Eds.), The Family and Social Change in Chinese Societies (pp. 165-175). Dordrecht: Springer.

https://doi.org/10.1007/978-94-007-7445-2_10

Chen, F., Liu, G., \& Mair, C. A. (2011). Intergenerational Ties in Context:

Grandparents caring for Grandchildren in China. Social Forces, 90(2), 571-594, https://doi.org/10.1093/sf/sor012

Cohen, M. L. (1976). House united, house divided: The Chinese family in Taiwan.

New York: Columbia University Press.

Cong, Z., \& Silverstein, M. (2012). Custodial grandparents and intergenerational support in rural China. In K. M Mehta. \& L. L. Thang (Eds.), Experiencing grandparenthood. An Asian perspective (pp. 109-127). Dordrecht: Springer. https://doi.org/10.1007/978-94-007-2303-0_7

Fei, X.T.费孝通 (1998[1947]). From the Soil: The Foundations of Chinese Society乡

土中国. Beijing: People's Publishing House 人民出版社.

Goh, E. C. L. (2009). Grandparents as childcare providers: An in-depth analysis of the case of Xiamen, China. Journal of Aging Studies, 23(1), 60-68.

https://doi.org/10.1016/j.jaging.2007.08.001

Hansen, M. H., \& Svarverud, R. (Eds.) (2010). iChina, the Rise of the Individual in Modern Chinese Society. Copenhagen: NIAS Press. 
Hoffman, L. (2010). Patriotic Professionalism in Urban China: Fostering Talent. Philadelphia: Temple University Press.

Hofstede, G., \& Bond, M. H. (1988). The Confucius Connection: From Cultural Roots to Economic Growth. Organizational Dynamics 16(4), 5-21.

https://doi.org/10.1016/0090-2616(88)90009-5

Ikels, C. (2004). Filial piety: Practice and discourse in contemporary East Asia. Stanford, CA: Stanford University Press.

Ko, P-C., \& Hank, K. (2014). Grandparents Caring for Grandchildren in China and Korea: Findings From CHARLS and KLoSA. The Journals of Gerontology: Series B, 69(4), 646-651. https://doi.org/10.1093/geronb/gbt129

Li, H. F. 李红飞,\& Gan, M. T. 甘满堂 (2017). Research on the Community Integration and Social Work Intervention of the Elderly Immigrating to the City: A Case Study of Shenzhen L Community随迁老人的社区融入及社会工作介入研究— 以深圳市L社区为例. Social Work and Management社会工作与管理, 17(1): 3137.

Lin J.-P. \& Yi, C.-C. (2011). Filial norms and intergenerational support to aging parents in China and Taiwan. International Journal of Social Welfare, 20(1), 109-120. https://doi.org/10.1111/j.1468-2397.2011.00824.x

Lu, L. (2001). Understanding Happiness: A Look into the Chinese Folk Psychology. Journal of Happiness Studies. 2(4):407-432. https://doi.org/10.1023/A:1013944228205

Mehta, K. M., \& Thang, L. L. (Eds.) (2012). Experiencing grandparenthood. An Asian Perspective. Dordrecht: Springer. https://doi.org/10.1007/978-94-007-2303-0 Meng, X. J, 孟向京, Jiang, X Q. 姜向群, Song, J.宋健, Wan H. X.万红霞, Chen, Y. 陈 艳, Han, Z. H. 韩中华, \& He, Y. Y. 何云燕 (2004). Analysis of characteristics and migrating causes of aged mobile population in Beijing北京市流动老年人口特征 及成因分析. Population Research人口研究 28(6), 53-58.

Mishler, E. G. (1986). Research interviewing: Context and narrative. Cambridge, MA: Harvard University Press. 
National Population and Family Planning Commission 国家计生委 (2017). Report on China's Migrant Population Development 中国流动人口发展报告2017. Beijing: China Population Publishing House. 中国人口出版社.

Nedelcu, M. (2017). Transnational grandparenting in the digital age: Mediated copresence and childcare in the case of Romanian migrants in Switzerland and Canada. European Journal of Ageing, 14(4), 375-383. https://doi.org/10.1007/s10433-017-0436-1

Riessman, C. K. (2008). Narrative methods for the human sciences. Los Angeles: Sage Publications.

Silverstein, M., Cong, Z., \& Li, S. (2006). Intergenerational transfers and living arrangements of older people in rural China: Consequences for psychological well-being. Journals of Gerontology, Series B, 61(5), 256-266. https://doi.org/10.1093/geronb/61.5.S256

Skytte, M. (2001). Etniske minoritetsfamilier og sosialt arbeid. Oslo: Gyldendal Norsk Forlag.

Special Rules on the Labor Protection of Female Employees (女职工劳动保护特别规 定) (2012). Retrieved from http://en.acftu.org/28616/201408/26/140826131330762.shtml (accessed 14 August 2016).

Wang, Y. (2006). Value changes in an era of social transformations: Collegeeducated Chinese youth. Educational Studies, 32(2): 233-240. https://doi.org/10.1080/03055690600631150

Whyte, M. K. (1997). The fate of filial obligations in urban China. The China Journal, 38(7), 1-31. https://doi.org/10.2307/2950333

Wu, L. (2013). Decentralization and hukou reforms in China. Policy and Society 32(1). https://doi.org/10.1016/j.polsoc.2013.01.002

Xie, X., \& Xia, Y. (2011). Grandparenting in Chinese Immigrant Families. Marriage \& Family Review, 47(6), 383-396. https://doi.org/10.1080/01494929.2011.594218 Yan, Y. X. (2003). Private life under socialism: Love, intimacy, and family change in a Chinese village, 1949-1999. Stanford: Stanford University Press. 
Yan, Y. X. (2011). Individualization of the family in rural China. Boundary 2 38(1): 203-229. https://doi.org/10.1215/01903659-1262590

Yan, Y. X. (2015). Parent-driven divorce and individualization among urban Chinese youth. International Social Science Journal, 213/214: 317-330. https://doi.org/10.1111/issj.12048

Yan, Y. X. (2016). Intergenerational Intimacy and Descending Familism in Rural North China. American Anthropologist, 118(2): 244-257. https://doi.org/10.1111/aman.12527

Yan, Y. X. (2017). Intergenerational Relatedness and Neo-Familism in Contemporary China. Keynote Speech at the $6^{\text {th }}$ Sino-Nordic gender and Women's Studies Conference: Age, Agency and Ambiguity, Oslo, Norway, Aug. 26-30.

Ye, W. (2013). Internal Migration and Citizenship Education in China's Shenzhen City. Education and Society, 48(1), 77-97. https://doi.org/10.1177/0013124513508775

Zhong, X., \& Li, B. (2017). New intergenerational contracts in the making? - The experience of urban China. Journal of Asian Public Policy, 10(2), 167-182. https://doi.org/10.1080/17516234.2017.1290864 